\title{
The black scourge? Race and the Rockefeller Foundation's tuberculosis commission in interwar Jamaica
}

\author{
O "flagelo negro"? Raça e \\ a comissão de tuberculose \\ da Fundação Rockefeller na \\ Jamaica do entreguerras
}

Henrice Altink

Reader in Modern History, University of York.

University of York, Heslington

YO10 5DD - York - England.

Henrice.altink@york.ac.uk
ALTINK, Henrice. The black scourge? Race and the Rockefeller Foundation's tuberculosis commission in interwar Jamaica. História, Ciências, Saúde Manguinhos, Rio de Janeiro, v.24, n.4, out.-dez. 2017, p.1071-1087.

\section{Abstract}

From 1927 to 1942, the Rockefeller Foundation ran a tuberculosis commission in Jamaica that researched the epidemiology of the disease, examined the efficacy of a vaccine with heat-killed tubercle bacilli, and offered basic treatment to tuberculosis sufferers. Drawing upon diaries and scientific writings by the staff employed by the commission, among other sources, this article explores the role that race played in the tuberculosis commission. It assesses how race shaped the research conducted by the commission, how it informed staff interactions and staff/ patient relations, and the clash and/or confluence of "imported" and local racial ideas in the commission's work.

Keywords: tuberculosis; race; Caribbean; global health; Rockefeller Foundation.

\section{Resumo}

De 1927 a 1942, a Fundação Rockefeller criou uma comissão da tuberculose na Jamaica que pesquisou a epidemiologia da doença, verificou a eficácia de uma vacina com bacilos da tuberculose que morriam com o calor e ofereceu tratamento básico para pacientes com tuberculose. Com base em anotações e textos científicos do grupo contratado para a tarefa, este artigo investiga a função da raça na comissão da tuberculose. Ele avalia como a raça moldou a pesquisa conduzida, como ela informou interações na equipe e relações equipe/ paciente, e o confronto e/ou a confluência de ideias raciais "importadas" e locais no trabalho da comissão.

Palavras-chave: tuberculose; raça; Caribe; saúde global; Fundação Rockefeller. 
F om 1927 to 1942, the Rockefeller Foundation's International Health Division (IHD) ran a tuberculosis (TB) commission in Jamaica that researched the epidemiology of the disease, examined the efficacy of a new vaccine, and offered basic treatment. The commission was led by Dr. Eugene Opie, a leading American TB expert, and employed various other North American doctors and researchers. As was common with other IHD projects in the region, the commission also relied heavily on local staff. This article, which is based on the diaries of the commission's staff and correspondence between the commission and IHD headquarters in New York (among other sources), explores the role that race played in the Jamaican TB commission. It initially explains how and why the commission was established, and depicts the nature of its work before moving on to explore the role that race played in the research carried out by the commission. Finally, it examines the role of race in staff interactions and staff/patient relations.

By centralising race within the Jamaican TB commission, this paper adds to three interlinked sets of scholarship. First, it contributes to existing work on TB; since the 1989 publication of Randall Packard's White plague, black labour: tuberculosis and the political economy of health and disease in South Africa, various studies have been published on TB outside of Europe and North America, including several on the (former) British Empire. The latter are more concerned with epidemiological and pathological understandings of TB and with institutions established to cure this disease in the colonies than with attempts to control and prevent it, and they also focus mainly on India and Africa (Brimnes, 2007; Harrison, Worboys, 1999; Worboys, 1999). Second, this study augments the scholarship on Caribbean health and medicine. While colonial medical history has been an established sub-discipline within the history of medicine since the 1980s, Caribbean medical history is a relatively new field ${ }^{1}$ and the few existing studies have largely ignored TB (McCollin, 2009; Heuring, 2011; Jones, 2013). And third, this article adds to existing literature on the history of global health; ${ }^{2}$ in particular, it adds to work on the history of international health organisations, including the forerunners of the WHO such as the Pan American Sanitary Bureau (PASB) and the IHD, the most important health agency working in Latin America and the Caribbean in the interwar years. Existing studies on the IHD have not only largely ignored TB, they also did not explore in any detail the various ways in which race informed the organisation's work and how this in turn helped uphold existing racial hierarchies. ${ }^{3}$

\section{The TB commission}

In 1912, TB was made a notifiable disease in Jamaica. At that time there had been 68 cases, nearly all pulmonary. The numbers soon increased; in 1927 there were 797 cases, and a death rate of 13.4 per 10,000 people, which was nearly three times the rates in the UK and US (Opie, Isaacs, 1930, p.3-4). Yet Jamaica lagged far behind some other Caribbean colonies in tackling the disease. Up to 1927, the only institution that provided care for TB patients was the poorhouse, but it only catered to those in the most advanced stage of the disease (p.6). In 1927, the IHD noted from a report by Dr. Benjamin Washburn, the head of the IHD in Jamaica, that TB was one of the main causes of death in the island. It subsequently informed its chief medical officer, Dr. Wilson, that if the Jamaican government deemed it 
useful and a "competent man be secured for the purpose," the Rockefeller Foundation could assist in undertaking a TB survey. The report stressed that although the survey would be done through the government medical department and placed under the direction of the chief medical officer, there was no need for a "vote of funds by the government." Because all government expenditures had to be paid from local revenue (which was very limited), this did much to persuade Wilson; the doctor became even more supportive when he was told that the IHD had secured the services of Dr. Eugene Opie. Opie was the director of the Henry Phipps Institute for the Study, Prevention and Treatment of TB at the University of Pennsylvania in Philadelphia, an institute with a state-of-the-art laboratory, a 50-bed hospital, and large outdoor clinics (Washburn, 6 Jul. 1927, 5 Dec. 1927; Wilson, 14 Jul. 1927, 11 Nov. 1927). ${ }^{4}$ Opie became the consultant for the commission, which meant that he trained staff sent from North America, visited the island once or twice a year, and oversaw the results of tests submitted by local staff.

By 1927, the IHD was already carrying out work in Jamaica, ranging from hookworm, malaria and yaws control projects, and school dental clinics to the formation of parochial health departments (Jones, 2013, chap. 6). Up to this point, the IHD had avoided TB work on the island because of the Rockefeller Foundation's experience with TB control in France during and in the immediate aftermath of First World War. In May 1917, it set up a French TB commission that included two hundred dispensaries and four mobile educational units. After the war ended, problems related to the French government's financial contribution to the commission and other issues soon accumulated, and by the end of 1922 the work of the IHD's TB commission in France had virtually ended (Farley, 2003, chap. 3; Picard, 1999). Wycliffe Rose, the IHD's director, and his successor Fredrick Russell regretted the IHD's involvement in $\mathrm{TB}$ control and vowed to never involve the institution in TB control work again. This was largely because at that time, TB was unlike most of the other diseases that the IHD worked on (like hookworm or yellow fever) because there was no insect that could be singled out as the main vector and fought with a "magic bullet." In fact, when the IHD undertook its work in France, TB was generally acknowledged as a social disease which had no quick fix; the only cure at that time was a good diet, sunlight, and rest.

But by the late 1920s the idea that TB was curable became more prevalent, as patients with mild cases of TB were sent to sanatoria, some with artificial pneumothorax (collapsed lung) had recovered, and experiments with a vaccine were conducted (Farley, 2003, p.185). As a result, the IHD became less averse to undertaking TB work. Yet its experience in France meant that it did not want to offer treatment to TB sufferers in Jamaica, but rather merely provide the Jamaican government with a set of recommendations on how best to prevent, control, and treat TB (Howard, 17 Mar. 1928). To do so, Opie needed more accurate information about its prevalence and nature than the statistics provided by the registrar-general, because many cases and particularly deaths from TB went unrecorded since patients did not alert medical authorities, or because these authorities failed to recognise TB. To obtain this more accurate information, Washburn (who had been appointed local director of the TB commission) conducted tuberculin tests in a few schools; lung tissue was gathered from the general hospital, the mental hospital and the poor house in Kingston, and a TB clinic was set up in Kingston in July 1928 with the specific aim of gathering reliable data (Farley, 2003, p.188). 
This and the later field surveys in rural parts of Jamaica and trial with a heat-killed tubercle bacilli vaccine illustrate that, like other IHD campaigns on the island, the main focus of the TB commission was research, not treatment or eradication.

\section{The clinic}

The clinic was the focal point of the TB commission during the first few years. It offered basic treatment and relief for TB patients by encouraging people to be tested with a tuberculin test, and follow-up if the test proved positive. Since its main aim was to gather data for the TB survey, the medical officer in charge of the clinic, one of its two nurses, and a clerk were all paid for by the IHD, but the building was provided by the Jamaican government, which would take over the clinic after completion of the survey and convert it into a testing and treatment facility. Washburn worked together with Wilson to select the medical officer and a nurse from the Jamaica Medical Service. They initially looked for a doctor with experience in TB work, but since none was immediately available, they appointed the white, locally-born Dr. Joyce Isaacs. She had a medical degree from University College London, and had been a resident obstetric assistant and casualty officer at Westminster Hospital. In addition, Helen Walker, a white, English-born woman and former matron of the Kingston hospital, was appointed the clinic's head nurse. The local Anti-Tuberculosis League (ATL) provided and paid for a second nurse, while one of the health visitors employed by the Kingston and St. Andrew Corporation (KSAC) was ordered to work under the direction of the clinic. These two black nurses were mainly involved in home visits. Finally, Margaret Manning, another white, locally-born woman, was appointed clerk for the clinic (Opie, 6 Jul. 1928).

The Kingston clinic followed the procedure established by the Henry Phipps Institute for the collection of data. Each patient received a serial number; as soon as a patient tested positive, his family was placed on a visiting list and received a family number. In a folder under the family number, records were then collected for all members of the household. A nurse visited the family at regular intervals, observing and recording their housing and habits and also giving advice on how they could protect themselves (Farley, 2003, p.186-187; Opie, Isaacs, 1930, p.8-9). The Phipps procedure was somewhat adapted to the conditions in Kingston; for instance, finances did not allow the clinic to routinely take X-rays, like the Phipps Institute did. Isaacs completed regular reports that she forwarded to Opie, who in turn informed Dr. Howard at IHD headquarters about progress. In 1930, the clinic moved to a new and larger building that included an X-ray laboratory. This, along with publicity work by the ATL, led to an increase in patients, and by 1931 3,208 patients had already been registered (Program..., 1932).

In 1930, a decision was made to enlarge the scope of the survey beyond the clinic, and Edward Flahiff and Hugh Smith (Canadian and American, respectively) were appointed for this work. After brief training at the Phipps Institute, the men were sent out do field work, first in Smith village, located on the outskirts of Kingston, and later in other parts of the island. ${ }^{5}$ This field work, which was closely modelled on the method employed by the IHD's hookworm commission, consisted of a medical officer and nurse moving from house to house in an area and administering tuberculin tests. If people tested positive, they were given a note to report for an X-ray, and in some small towns and rural areas they were even provided transport to 
the nearest X-ray laboratory. Anyone who failed to appear for an X-ray examination received a home visit. Men and women whose X-rays showed lesions were required to give sputum samples, given a thorough physical examination, and had a detailed history taken. By 1932, the commission acquired a mobile X-ray unit, which considerably sped up the process (Flahiff, 1938, p.563-564). In most areas, roughly 65 to 90\% of the population agreed to take a tuberculin test, a very high take-up rate. It is also noteworthy that until that time, such a wide-scale TB survey had not been conducted anywhere in the world. The field survey, along with the opening of five other clinics, led to the appointment of more local black nurses and also required more clerical staff to enter data, as well as a driver, an assistant medical officer, and more specialist staff. Dr. Clifford Wells, for instance, was appointed head of the $\mathrm{X}$-laboratory and was assisted by a locally-born doctor who already had some experience in X-ray work (Report..., 1931).

\section{The trial}

The TB commission not only gathered data to provide the government with a plan on how best to control TB, it also conducted a vaccine trial, which Washburn regarded as "probably the most important feature of our tuberculosis programme" (Washburn, 12 Aug. 1931). Research into a vaccine for TB started in the early twentieth century, and by 1921 the French scientists Albert Calmette and Camille Guerin of the Pasteur Institute began to test their live vaccine (BCG) on human beings. Between 1924 and 1928, approximately 114,000 infants susceptible to TB were vaccinated with BCG. A drop in the mortality rate among these vaccinated children suggested that the vaccine was effective. Yet many still questioned the efficacy of BCG and sought an alternative vaccine, which received further impetus after the 1930 "Lübeck Disaster" in Germany, when 73 of 250 vaccinated babies died and 135 became infected and never recovered (Luca, Mihaescu, 2013, p.53-58). An alternative to the live BCG was vaccination with heat-killed tubercle bacilli. One of the scientists involved in developing this vaccine was Eugene Opie. In 1932, he had taken a position at Cornell University, where he and his team first tested the vaccine on rabbits. When these animal trials showed positive results, the vaccine was then tested on patients in the Jamaican mental hospital.

Most patients at the mental hospital came from rural districts with little exposure to TB. There were about 2,500 patients, with around 540 new admissions each year. Except for ill and more violent patients, the hospital provided access to large compounds (one for each sex) with no restrictions on movement. This arrangement, along with overcrowded sleeping quarters, facilitated the spread of TB. The hospital provided an excellent opportunity to study the spread of contagion, and the commission therefore included it very early on in its TB survey. Initially, it was just interested in following patients who tested negative for TB upon admission and determining how quickly they developed the disease (Opie, 15 Mar. 1929). From 1932 onwards, half of all newly-admitted patients who were found negative for TB on admission were vaccinated with heat-killed tubercle bacilli, and the other half were designated controls (Report..., 1938). Initially, the vaccinated group was injected every week for up to ten weeks, but gradually a single injection was used and the participants were tested seven weeks later. If they tested negative, they were given another injection. Both the vaccinated 
and control groups were given a tuberculin test and an X-ray every three to four months for the duration of their hospitalisation (Program, 1932).

Between 1932 and 1938, about 210 patients were given the vaccine and 206 were used as controls. Twenty-three patients in the vaccinated group and 39 in the control group developed $\mathrm{TB}$, while 16 of the vaccinated group and 27 of the controls died from TB. The conclusion of this trial was that the heat-killed tubercle bacilli vaccine offered some protection in the first eighteen months after vaccination, and that it would be useful for groups at high risk of infection, such as medical students and trainee nurses. But this conclusion was acknowledged to be problematic, since the vaccinated group had been exposed to severe infection at the time when they were acquiring immunity, while the controls that did not get manifest TB seemed to have acquired infection and were protected by it (Wells, Flahiff, Smith, 1939, 1944).

The vaccine trial was gradually extended beyond the mental hospital to children, because the population in the mental hospital was relatively old and the vaccine's impact on a younger age cohort needed to be ascertained. Approximately 300 children at the Stony Hill Industrial School, Alpha Orphanage, and Maxfield Orphan Asylum were vaccinated and a similar number used as controls. From 1939 onwards, the trial was rolled out to children in selected schools, largely because teachers were "willing and eager to aid in securing the vaccination" of school children (Washburn, 4 Jul. 1938). The children were given a "permit slip" to be signed by parents or guardians several days prior to the tuberculin test, which authorised them to be tested and vaccinated if necessary. The commission hoped that the schools taking part in the trial would be "the channel for broadcasting our work to the homes in the district" (Flahiff, 1939). Finally, the tests and vaccinations were extended to the general population and performed in several colleges, the Venereal Disease Clinic, the outpatient department of the public hospital in Kingston, and also during house-to-house visits in both Kingston and rural areas. Additionally, nursing students and members of the constabulary and military forces were tested and vaccinated when necessary. Table 1 provides a summary of the general population vaccination trial between 1939 and 1942. The trial came to an end in 1942, when results showed little difference between vaccinated and non-vaccinated groups. In total, 9,167 Jamaicans were vaccinated with the heat-killed tubercle bacilli vaccine between 1932 and 1942 (Bryder, 1999, p.1163).

Table 1: Vaccination trial, general population 1939-1942

\begin{tabular}{l|c|c|c}
\cline { 2 - 4 } & Kingston & Rural areas & \multicolumn{1}{c}{ Total } \\
\hline Tested & 14,078 & 30,204 & 44,282 \\
\hline Percentage $<15$ years of age tested & $41 \%$ & $33.7 \%$ & $36 \%$ \\
\hline Vaccinated & 1,456 & 2,230 & 3,686 \\
\hline Controls & 1,357 & 2,240 & 3,597 \\
\hline
\end{tabular}

Source: Wells, Flahiff (1944, p.109-110).

Existing data do not indicate whether the adults who participated in the trial or gave permission for their children to be vaccinated were fully aware of what they were participating in. The fact that many were eager to take part should initially be considered in light of the publicity around the general population trial. While the trials in the mental hospital, 
industrial school, and orphanages were never mentioned in public, the general population trial was regularly and positively mentioned in the island's main newspaper, The Gleaner. In fact, the IHD even placed advertisements in the paper calling upon people who had recently migrated to Kingston to get vaccinated. Additionally, the general population trial was also mentioned in a radio broadcast by Richard Cory, the island's TB officer, in 1939. The fact that so many people came forward can also be explained by the low standard of medical care. As mentioned, TB was a leading cause of death before the arrival of the TB commission. In 1934, Opie provided the government with a set of recommendations for controlling and treating the disease. However, a lack of funds meant that the government could not implement all the recommendations, so by the late 1930s there was still relatively little available to treat TB sufferers. There was a TB hospital in Kingston (run by the KSAC), and most but not all poor houses had a TB ward, but these were the last resort for TB patients. Consequently, many people welcomed a "magic bullet" to prevent TB infection.

\section{Race and research}

As mentioned above, the main focus of the Jamaican TB commission was research. First of all, it tried to assess the prevalence, nature, and spread of TB. When the survey was extended beyond the Kingston clinic, it soon became apparent that the incidence of the disease was lower in rural parishes than urban ones. The results also revealed that TB was mostly confined to adults, with a very rapid course; however, the survey also tried to assess whether black people were more susceptible to TB than whites, and/or whether the disease took a different course in blacks. ${ }^{6}$ Opie had already examined differences between white and black patients at the Phipps Institute; the data collected in Jamaica certainly allowed him to explore in more detail whether the "characters, clinic course and mode of spread" in blacks varied from that of whites (Report..., 1932).

To assess the impact of race, the forms used by the clinic and in field work included data on skin colour. Like other IHD projects in the Americas, the TB commission struggled to devise a racial classification system and map people onto it (Palmer, 2010, p.132-133). It came up with a range of skin colour designations that were a mix of locally-used and imported terms: black, dark brown, light brown, pale brown, white, East Indian, and Chinese. An additional locally-used designation, "Sambo brown," was added in 1932. Staff particularly struggled to place "racial mixtures," such as African-Chinese people. Should these be entered under "light brown with no reference to the racial mixture? Or should additional categories be added for half Chinese, half Syrian, or half something else?" (Smith, 29 Oct. 1932). It is very likely that locally-born staff placed participants into different categories than expat staff did. Factors such as education, income, speech, propriety, and ownership of property affected how locals perceived skin tone. If they considered a person to be of the more common type, they would place them in the categories on the darker side of the colour spectrum. But if they saw them more as a member of the better class, they would place them in any of the categories on the lighter side. Consequently, a dark-skinned head teacher was more likely to be classified "Sambo brown" rather than "black" because of his occupational status (Altink, forthcoming, chap. 3). 
Because there were so few whites, Chinese, and East Indians affected with TB, the studies published by the TB commission concentrated on "the Negro race." This term was not commonly used in Jamaica at the time, not even by the colonial government, which used white, black, coloured, Chinese, East Indian, and other to designate race in the census and official correspondence. Therefore, the use of the term "Negro race" clearly indicates that the studies were geared first and foremost towards the American medical establishment. The commission concluded that TB in "the Negro race in Jamaica" differed from TB in whites in Europe and America, following a more rapid and fatal course and spreading more quickly among this group. But in adding that more African Jamaicans than "American Negroes" showed tubercle bacilli in their sputum and had more "infiltrating pulmonary lesions of the childhood or first infection type," the TB commission suggested that race was not the main explanatory variable. In fact, they attributed the "more rapid course" and type of TB that affected "Jamaican Negroes" to their socio-economic circumstances and culture: "uncleanly habits, unhygienic housing conditions, and lack of facilities for segregation of those who suffer with the disease" (Putnam, Saward, Opie, 1941, p.22, 31).

As early as their first report, which was published in 1930 and based on data gathered by the clinic, Isaacs and Opie had attributed some of the marked differences in the incidence and nature of the disease between Jamaican "Negroes" and Philadelphia whites to culture. For instance, they concluded that not only poverty but also particular habits facilitated the quick spread of the disease, such as "promiscuous relations" and ignorance of "habits of cleanliness" (Opie, Isaacs, 1930, p.19-20). Thus, while officers of the TB commission did not state that black people were naturally predisposed to TB or a particular type of TB, they still saw race as a factor in the epidemiology of $\mathrm{TB}$, one which was now packaged as "culture" rather than "nature." It can therefore be argued that their reports reflect the onset of a shift from scientific to cultural racism which gained momentum after Second World War (Barkan, 1992).

Even though the evidence gathered showed, almost from the start, that TB was a social disease and that certain racial groups were not predisposed to it, many IHD staff could not shake off their belief that blacks were naturally more susceptible. For instance, Rufus Cole (1931), the scientific director of the IHD, remarked that the findings of the TB survey "would be applicable not only to other tropical countries" but also to "our Southern States. And the commission's preoccupation with the role of skin colour equally demonstrates a reluctance to let go of the idea that race in and of itself played a role in the transmission and nature of the disease. The TB commission was not just concerned with whether TB was different in blacks and whites, but also tried to assess whether there were any marked differences between "black" and lighter-skinned African Jamaicans with regards to the incidence and nature of TB. This focus most likely was the product of concern expressed at that time by various groups in America about racial intermixing. In fact, it was not the first time that Jamaica was used as a laboratory to assess the impact of racial mixing. Elsewhere I have explored a 1927-1928 study by the American Eugenics Record Office to assess the impact of human miscegenation. In this study, some 100 "blacks," 100 "browns," and 100 "whites" were subjected to various physical and mental tests, and the authors argued that there were physical and mental disharmonies amongst the hybrid race of the "browns" which warned against racial mixing (Altink, 2007). 
A preliminary report on the role of colour in TB transmission was completed in 1934, based on surveys conducted in four parts of Kingston which had similar class status. Although the population was given one of the aforementioned colour designations, for this study they were divided into two broad categories: "black and dark brown" and "light brown and others." On the basis of X-rays, the report concluded that "childhood lesions did not vary with colour but that adult lesions increased definitely as colour shades became lighter" (Putnam, 24 Sept. 1934). The relation between colour and incidence and nature of the disease was also addressed in the survey of rural areas of Jamaica. But here, where more than 90 per cent of the population was described as "black," the survey found that the "tuberculin reaction among persons of racial mixture does not differ in frequency from that of those wholly Negro" (Wells, Flahiff, Smith, 1939, p.155). Therefore, over time there was less insistence that race and colour in and of themselves enhanced the risk of contagion or nature of the disease, and greater emphasis was placed on socio-economic factors - urban versus rural, middle class versus lower class etc.

Race was not only a variable in the epidemiological research of the TB commission, but also the reason why the vaccine was tested in Jamaica. The Jamaican trial was one of several experiments in the years surrounding Second World War in which black bodies were used to advance American medical science. The most well-known example is the Tuskegee syphilis experiment, which between 1932 and 1972 followed but did not treat 439 men with latestage syphilis and 185 controls without the disease. Another example which has emerged more recently is the US Public Health Service's STD study in Guatemala, in which 1300 men and women were infected with syphilis and other STDs between 1946 and 1948 but only half were treated (Reverby, 2012; Washington, 2006). Like the Eugenics Record Office experiment, Opie's choice to test the vaccine in Jamaica (rather than Philadelphia or any other part of the US) resulted from the fact that conditions in the island made it relatively easy to do this research. Jamaica was an English-speaking country, and had a chief medical officer interested in preventive TB work who helped the commission secure human subjects without involving a consent process. It would have been far more difficult (although not impossible, as the Tuskegee experiment shows) to undertake such a widespread trial in the US. It would have been harder to find officials who agreed to conduct trials in orphanages and mental hospitals on American soil, and race relations were so poor that it would also have been more difficult to get adult black men and women to take part in a vaccination trial once experiments with selected groups were completed.

The vaccine trial started in the mental hospital, moved to the orphanages and industrial school, and was finally rolled out to selected schools and the general population. It is not surprising that the trial started with groups who were not in a position to consent; as Washburn told Howard, in Jamaica "as elsewhere people don't like to feel that they are being 'experimented' upon" (Washburn, 24 Mar. 1931). Nearly all the patients in the mental hospital and the children in the orphanages and industrial school were "black" and "dark brown" because of the close link between class and colour at the time. We do not know what they were told about the tests that they were subjected to and the inoculations they received - while most received a single injection, others were given multiple injections - but it is 
unlikely that many would have questioned this process. They were then, as John Farley has argued more generally of people who took part in IHD research, "convenient guinea pigs" .

Even though the general population trial was reported in the newspaper, it would appear that these reports did not clearly convey the fact that not everyone would be vaccinated. In fact, the commission feared that many of the controls would demand inoculation. It also understood fully that it would be difficult to follow the vaccinated and control groups in the poorer sections of Kingston where the population was very unstable, a problem that also plagued the Tuskegee experiment (Memorandum..., 1942). Flahiff made a suggestion to counteract this problem: an additional trial in a rural part of Quebec where TB was also highly prevalent, but the population was fairly stable. Yet he soon questioned this, because it might be "much more difficult" to explain to the Quebecois than to the Jamaicans why some individuals were vaccinated and others were not (Flahiff, 8 Nov. 1938). So again, we see that stereotypical ideas of race informed the work of the commission. Flahiff clearly assumed that African Jamaicans were less intelligent than white Canadians and could thus more easily be fooled into accepting why they were not vaccinated.

\section{Race and staff interaction and staff/patient relations}

In countries with significant racial minorities (or majorities, in the case of the British West Indies), dominant ideas about race and colour informed the IHD's employment of local staff. Steven Palmer (2006, p.23), for instance, has shown that the US directors of the hookworm commissions in Guyana and Trinidad favoured Indo-Caribbean men as microscopists, but preferred black men as home visitors. The Jamaican TB commission was marked by a similar racial hierarchy: the most senior posts were held by white (local or expat) staff, and the most junior posts were occupied by dark-skinned Jamaicans. At the time, there were AfricanJamaican doctors, who like Isaacs were well-trained and lacked experience in TB work. Yet none of these were ever considered for the post, and it was Richard Cory, a locally-born white doctor, who was appointed as Isaacs' assistant. The IHD was convinced that it was best to appoint black nurses for both home visiting work and the field surveys, "as it would be easier for them to adjust themselves to local conditions" (Washburn, Oct. 1936).

Yet the most prestigious nursing positions like head clinic nurse were reserved for white women. When Helen Walker resigned in 1930, the aim was to replace her with another white woman. On an island where whites made up less than $2 \%$ of the total population and nursing was seen as a lower-middle-class profession, the administrators quickly realised that this would not be easy unless the Overseas Nursing Association could be asked to supply a nurse from England. Because this would take too long, the next suggestion was to offer the position to a "brown girl," who had only been at the clinic for two months but was seen to be "by far the best nurse with any coloured blood" (Carley, 15 Jul. 1930). This "brown" nurse was clearly regarded as second-best. And to further illustrate that white women were preferred for the more senior nursing posts, when Clifford Wells was appointed in 1932, Howard asked if it "would be possible to get a suitable white nurse in Jamaica" to work with him. This is unsurprising considering concerns about racial mixing in the US at that time, since Wells would have had to work closely with this nurse. Attempts were made to meet 
this request; a Mrs. Dun, the white wife of a local government official who had been trained and worked as an X-ray technician in the US, was seen as the ideal candidate, and also came highly recommended by the chief medical officer (Howard, 2 Jul. 1930).

The racial hierarchy within the TB commission closely resembled that of the government medical service. The most senior positions in the government medical service, such as matron or head of a hospital, were always held by white expats. Local whites were the second-highest ranking officers. As I have shown elsewhere, these were often appointed to posts for which there were more experienced or better-qualified African Jamaicans available. Some (mostly very light-skinned $)^{7}$ African-Jamaican doctors and nurses occupied fairly high roles in the service, but they were only appointed to more senior posts in an acting capacity. Finally, the bottom rung of the government medical service was comprised of untrained or poorly trained nursing staff, such as mental hospital attendants and rural midwives (Altink, 2012, 2013).

The sources on which this article is based reveal little overt discrimination on the part of white expat staff towards black staff, such as that expressed by Dr. Cornelius Rhoads, who conducted research for the IHD on anaemia in Puerto Rico and complained that Puerto Ricans were the "laziest, most degenerate and thievish race of men" (Farley, 2003, p.81). Yet they do reveal that North American doctors were informed by the racial prejudices and ideas of their own society. For instance, the IHD bio-statistician Hugo Muench visited Jamaica in 1932, and in the diary of his visit included several lists of made-up first names he had read while analysing data from the Kingston clinic, such as Viris and Synsent. These names, he argued, showed "imagination and some originality!" (Muench, 1932). The exclamation mark conveys that he, like many white Americans who deride black names today, did not mean this as a compliment. ${ }^{8}$ Wells, on the other hand, was highly critical of the non-white members of the commission. He wrote, for instance, that "one familiar with local personnel in Jamaica fully realizes their short-comings and the necessity for prolonged instruction and training" (Wells, 2 Feb. 1932). And John Weir, who worked on the general population vaccination trial, was also less than appreciative of local staff, claiming for instance that local nurses had developed a "Rockefeller Foundation complex," asking for taxis to take them to and back from work (Weir, 1939). Muench, Wells, and Weir drew upon stereotypical ideas about black people from their own society - namely that they were lazy, stupid etc. - and as Weir expressed most clearly, they were also keen to see a similar racial order, in which blacks knew their place.

But not all expat members of the commission held negative opinions about local black people. Washburn, for example, disputed Wells' observation, claiming that local staff were "as efficient as any I have had in any place in which I have worked" (Washburn, 5 Feb. 1931). And because Flahiff seemed to relate well to local staff, Opie decided to choose him over Wells to lead the vaccination trial, because "he is less likely to make up his mind beforehand and works in closer sympathy with his associates" (Opie, 1 Sep. 1937). Flahiff even went the extra mile for some local staff; for example, in 1939 he asked IHD headquarters if there was a possibility that Dr. Parkin, who assisted in taking X-rays in the field, could take a course in radiology in the US. He was asked to provide not only information about Parkin's "training and experience" but also whether he was "white or coloured" (Lambert, 15 Aug. 1939). This question points to the racism present in American hospitals at that time, because even in the unsegregated North there was a strong dislike of dark-skinned doctors (Byrd, Clayton, 
2001, p.21s). Because Flahiff was eager for Parkin to enter a course, he described him not as "coloured" but rather "'swarthy;' that is, nearer a light brown" (Flahiff, 8 Sept. 1939).

While there was a high take-up of the tuberculin test in the field survey, not all Jamaicans welcomed the commission and its work. When the commission extended its work beyond the clinic to a survey of selected areas in Kingston, they encountered considerable opposition from locals. In fact, even the locally-born sanitary inspectors, who conducted a census of each person living in the area and handed out letters to householders explaining the survey, were treated poorly. Rumours circulated that the tuberculin test was an instrument used by the "white race to destroy the coloured race." More specifically, the rumour stated that it would lead to infertility in women, which caused particular concern since lower-class men and women placed a high value on fertility. A successful means of overcoming this opposition was to also offer everyone who submitted to a tuberculin test an X-ray: the novelty of being able to see their own lungs on a screen led many men and women to take a test (Report..., 1931).

Like the sanitary inspectors, local nurses were also not immune from abuse. The nurses attached to the Kingston clinic, for instance, often had to deal with patients who did not want to be visited because their neighbours would realise they had TB and shun them (Report..., 1931-1932). Especially when the vaccination trial was rolled out across the general population, the nurses encountered much opposition. This should be seen especially in light of a birth control campaign which started around the same time and was widely reported in the press. ${ }^{9}$ Many men and women assumed that the nurses wanted to trick people into adopting birth control. Others refused to cooperate with the trial because they saw it as "a campaign initiated by the white people to poison all the black people in the island" (Flahiff, 1939). These two objections often merged together. One nurse, for example, encountered a soapbox orator in Trench Penn who told a crowd that "at present the black population was in ratio of 14 to 1 white man, that white people were, therefore trying to decrease the black population. That was why they were going around injecting people, particularly women, to dry up their wombs" (Flahiff, 1939). The island-wide labour riots which had occurred only a year earlier and did much to raise race consciousness also help explain this opposition to the vaccination trial. ${ }^{10}$

\section{Final considerations}

Studies published on race and medicine in recent years fall into two categories: narratives of abuse and suffering, and narratives in which non-white people triumph over adversity (Revereby, 2007). The story presented here is largely one of abuse: the bodies of the most vulnerable black Jamaicans were used to test a vaccine that first and foremost helped white bodies. It is less a story of non-white people triumphing over adversity. Although African Jamaicans did not accept the work of the TB commission without criticism, many welcomed the Kingston clinic and others that were set up in its wake, and willingly took part in the general population trial with the heat-killed tubercle bacilli vaccine. The sheer fact that TB was one of the main causes of death and that medical care was limited (as was the case in other British colonies with black majorities) largely explains why so many African Jamaicans did not actively resist the work of the commission. 
But this does not minimise the role race played in the work of the commission. The commission's research into the epidemiology of TB emerged out of a particular understanding of race; namely, that black and white were inherently different, and that this difference mattered when it came to disease. Although the commission concluded that it was not biology but rather socio-economic circumstances that explained why TB had such a rapid and fatal course in African Jamaicans, it struggled to shake off this belief that there was a natural difference between whites and blacks. Yet while race informed the commission's research into the transmission and nature of $\mathrm{TB}$, it did not shape its research into an alternative vaccine: it never attempted to assess whether white and black people responded differently to the vaccine, but merely wanted to test whether the vaccine was as effective in humans as it was in the rabbits Opie used in his lab at Cornell. But it is no coincidence that the vaccine trials were conducted on black rather than white bodies, since they were easily available and valued less. By conducting the trial on this group, the commission followed a long tradition in which black bodies were (mis)used to advance American medical science. During the era of slavery, African Americans (both patients and cadavers) were subjected to surgical and other medical experiments (e.g. Kenny, 2015). And this exposure to untried drugs and other experiments continued after emancipation, culminating in the Tuskegee syphilis experiment (Washington, 2006). Furthermore, as illustrated by the US Public Health Service VD experiment in Guatemala, among others, African Jamaicans were only one of several groups of black men and women outside the US at that time whose bodies were experimented upon by American medical scientists.

Race also informed staff interaction and staff/patient relationships. Expat members of the commission brought with them their particular understandings of race. They assumed that only whites were suitable for certain positions, and looked down upon the norms, values, and practices of African Jamaicans. As such, this study lends further support to existing work that exposes the structural racism integral to American medicine. But the commission was not alone; the government medical service also was not free from institutionalised racism. Many members of the commission were appointed by the chief medical officer, in liaison with Washburn and Opie. This meant that the staff hierarchy of the commission was effectively a race/colour/class hierarchy.

Although its nature differed greatly from the Tuskegee and Guatemala trials, the Jamaican TB commission's trial of an alternative vaccine and its research into the transmission and nature of TB also drew upon and helped reinforce the idea that black bodies had less value than white bodies. And even though it gradually came to see race as less of a biological and more of a socio-economic category, the commission's work was interwoven with assumptions about white superiority and black inferiority that shaped day-to-day interactions between staff on the one hand, and staff and patients on the other. While Jamaica and other former British Caribbean colonies have long been independent, they still act as convenient "laboratories" for American medical science. Johns Hopkins University, for instance, conducts out genetic research in Barbados, because this allows it "to ethically address the African diaspora without the quandaries of accusations and recriminations experienced in carrying out such work in urban America" (Whitmarsh, 2011, p.177). The reason why many African-Caribbean men 
and women today willingly participate in trials conducted by American researchers - often without being paid - is the same as that of the Jamaican men and women who attended the TB clinics and participated in the general population trial: namely, the low standard of local medical care. Consequently, an important lesson that this case study provides is that black bodies in the Caribbean and other parts of the Americas will continue to be (mis)used to advance American medical science unless governments provide their people with affordable and adequate medical care.

\section{NOTES}

${ }^{1}$ The first edited collection on the history of Caribbean health and medicine (De Barros, Palmer, Wright, 2009) was only published in 2009.

${ }^{2}$ Global health has been defined in different ways by different disciplines (e.g. Beaglehole, Bonita, 2010; Koplan et al., 2009). Here the term refers to health issues and initiatives that transcend national borders and aim to bring about health equity around the world. On the history of global health, see Packard (2016). For the rise of the subfield of global health history and its main themes and issues, see Harrison (2015) and Johnson (2016).

${ }^{3}$ There is a substantial body of work on the IHD. The first studies were mostly institutional histories; a second wave offered sharp criticism of the IHD, questioning its humanitarian claims and presenting it as little more than an instrument of US imperialism. But the most recent work on the IHD, which tends to focus on a single location or a single disease, has presented a more nuanced picture by paying as much attention to Rockefeller staff as local players, strategies, health traditions and institutions, and their interplay (e.g. Cueto, 1994; Palmer, 2010). In his "biography" of the IHD, John Farley (2003) devoted only four pages to the Jamaican TB commission, and touched only briefly upon race in IHD campaigns.

${ }^{4}$ Although Opie took a position at Cornell University in 1932, the IHD continued to finance his work. By then he had moved on to develop a "magic bullet" for TB: a vaccine with heat-killed tubercle bacilli (Farley, 2003, p.189).

${ }^{5}$ The men selected areas which allowed them to determine crucial factors in the spread and nature of the disease. Therefore some areas were isolated and others were more urban; some had higher or lower proportions of people with high socio-economic standing.

${ }^{6}$ The IHD also collected information on race and ethnicity in other places and for other diseases, but not always with the overt aim of determining whether race was a major factor in the nature and spread of the disease (Palmer, 2010).

${ }^{7}$ These men and women were mostly light-skinned because their positions required a secondary school education. And because class and colour were closely entwined at that time, it was mostly light-skinned boys and girls who went to secondary school (Altink, forthcoming, chap. 1-2).

${ }^{8}$ Even today, black first names in the US are often derided as "ridiculous" or "stupid" and men and women with names such as Keisha or LaTroy are treated less favourably than those with more Anglo-American names as Kate and John (Holbrook, Fessler, Navarette, 2016).

${ }^{9}$ Bourbonnais (2012) has explored this campaign in detail.

${ }^{10}$ Thomas Holt (1992) has provided a detailed account of the riots.

\section{REFERENCES}

ALTINK, Henrice.

Unveiling the public secret: race in colonial and independent Jamaica. Liverpool: Liverpool University Press. forthcoming.

ALTINK, Henrice.

A True Maverick: the political career of Dr.
Oswald E. Anderson, 1919-1944. New West Indian Guide, v.87, n.3-4, p.3-29. 2013.

ALTINK, Henrice.

Modernity, race and mental health care in Jamaica, c.1918-1944. Journal of the Department of Behavioural Studies, v.2, n.1. 2012. 
ALTINK, Henrice.

An American race laboratory: Jamaica, c. 18651940. Wadabagei, v.10, n.3, p.53-83. 2007.

\section{BARKAN, Elazar.}

The retreat of scientific racism: changing concepts of race in Britain and the United States between the world wars. Cambridge: Cambridge University Press. 1992.

BEAGLEHOLE, Robert; BONITA, Ruth. What is global health? Global Health Action, v.3, n.1. Disponible on: https://doi.org/10.3402/gha. v3i0.5142. Access on: 27 Nov. 2017. 2010.

BOURBONNAIS, Nicole.

Class colour and contraception: the politics of birth control in Jamaica, 1938-1968. Social and Economic Studies, v.61, n.3, p.7-37. 2012.

BRIMNES, Nils.

Vikings against tuberculosis: the international tuberculosis campaign in India, 1948-1951. Bulletin of the History of Medicine, v.81, n.2, p.407430. 2007.

BRYDER, Linda.

"We shall not find salvation in inoculation:" BCG vaccination in Scandinavia, Britain and the USA, 1921-1960. Social Science \& Medicine, v.49, n.9, p.1157-1167. 1999.

BYRD, W. Michael.; CLAYTON, Linda. A. Race, medicine, and health care in the United States: a historical survey. Journal of the National Medical Association, v.93, n.3, suppl., p.11d-34s. 2001.

CARLEY, Paul S.

Letter to Howard. Rockefeller Foundation (RF) Record Group (RG) 1.1. 437, box 5, folder 65 (The Rockefeller Archive Centre). 15 Jul. 1930.

COLE, Rufus.

Memorandum: trip to Jamaica. RF RG 1.1. 437, box 1, folder 2 (The Rockefeller Archive Centre). 1931.

CUETO, Marcos (Ed.).

Missionaries of science: the Rockefeller Foundation and Latin America. Bloomington: Indiana University Press. 1994.

DE BARROS, Juanita; PALMER, Steven; WRIGHT, David (Ed.).

Health and medicine in the Circum Caribbean, 1800-1968. London: Routledge. 2009.

FARLEY, John.

To cast out disease: a history of the International Health Division of the Rockefeller Foundation, 1913-1951. Oxford: Oxford University Press. 2003.
FLAHIFF, Edward Waller.

Diary, RF RG 12, box 154, folder Flahiff (The Rockefeller Archive Centre). 1939.

FLAHIFF, Edward Waller.

Letter to Sawyer. RF RG 2 437, box 181, folder 1305 (The Rockefeller Archive Centre). 8 Sept. 1939.

FLAHIFF, Edward Waller.

Tuberculosis survey in Jamaica. American Review of Tuberculosis, v.37, n.5, p.560-577. 1938.

FLAHIFF, Edward Waller.

Letter to Sawyer. RF RG 1.1. 437, box 8, folder 102 (The Rockefeller Archive Centre). 8 Nov. 1938.

HARRISON, Mark.

A global perspective: reframing the history of health, medicine, and disease. Bulletin of the History of Medicine, v.89, n.4, p.639-89. 2015.

HARRISON, Mark; WORBOYS, Michael.

A disease of civilisation: tuberculosis in Britain, Africa and India, 1900-39. In: Marks, Lara; Worboys, Michael (Ed.). Migrants, minorities and health: historical and contemporary studies. London: Routledge. p.93-124. 1999.

HEURING, Darcy Hughes. Health and the politics of improvement in British colonial Jamaica, 1914-1945. PhD Dissertation Northwestern University. 2011.

HOLBROOK, Colin; FESSLER, Daniel M.T.; NAVARETTE, Carlos David.

Looming large in others' eyes: racial stereotypes illuminate dual adaptations for representing threat versus prestige as physical size. Evolution \& Human Behavior, v.37, n.1, p.67-78. 2016.

HOLT, Thomas C.

The problem of freedom: race, labor, and politics in Jamaica and Britain, 1832-1938. Baltimore: Johns Hopkins University Press. 1992.

HOWARD, Hector Holbrook.

Letter to Carley. RF RG 1.1. 437, box 5, folder 65 (The Rockefeller Archive Centre). 2 Jul. 1930.

HOWARD, Hector Holbrook.

Letter to Opie. RF, RG 1.1. 437K, box 2, folder 27 (The Rockefeller Archive Centre). 17 Mar. 1928.

JOHNSON, Jennifer.

New directions in the history of medicine in European, colonial and trans-imperial contexts. Contemporary European History, v.25, n.2, p.38799. 2016.

JONES, Margaret.

Public health in Jamaica, 1850-1940: neglect, philanthropy and development. Kingston: University of the West Indies Press. 2013. 
KENNY, Stephen C.

Power, opportunism, racism: human experiments under American slavery. Endeavour, v.39, n.1, p.10-20. 2015.

KOPLAN, Jeffrey P. et al.

Towards a common definition of global health. The Lancet, v.373, n.9679, p.1993-95. 2009.

LAMBERT, Robert A.

Letter to Flahiff. RF RG 2 437, box 181, folder 1305 (The Rockefeller Archive Centre). 15 Aug. 1939.

LUCA, Simona Luca; MIHAESCU, Traian. History of BCG vaccine. Maedica, v.8, n.1, p.5358. 2013.

MCCOLLIN, Debbie.

World War II to independence: health services and women in Trinidad and Tobago, 1939-1962. In: De Barros, Juanita de; Palmer, Steven; Wright, David (Ed.). Health and medicine in the Circum Caribbean. London: Routledge. p.227-248. 2009.

MEMORANDUM...

Memorandum of Jamaica. Tuberculosis vaccination studies. RF RG 1.1. 437, box 9, folder 115 (The Rockefeller Archive Centre). 1942.

MUENCH, Hugo.

Diary. RF RG 1.1. box 1, file 1 (The Rockefeller Archive Centre). 1932.

OPIE, Eugene L.

Letter to Sawyer. RF RG 1.1. 437, box 8, folder 99. 1 Sept. 1937.

OPIE, Eugene L.

Letter to Howard. RF RG 1.1. $437 \mathrm{~K}$, box 2 , folder 28 (The Rockefeller Archive Centre). 15 Mar. 1929

OPIE, Eugene L.

Letter to Howard. RF RG 1.1. 437, box 1, folder 2 (The Rockefeller Archive Centre). 6 Jul. 1928.

OPIE, Eugene L.; ISAACS, E. Joyce.

Tuberculosis in Jamaica. The American Journal of Hygiene, v.12, n.1, p.1-61. 1930.

PACKARD, Randall M.

A history of global health: interventions into the lives of other people. Baltimore: Johns Hopkins University Press. 2016.

PACKARD, Randall M.

White plague, black labor: tuberculosis and the political economy of health and disease in South Africa. Berkeley: University of California Press. 1989.

PALMER, Steven.

Launching global health: the Caribbean odyssey of the Rockefeller Foundation. Michigan: University of Michigan Press. 2010.
PALMER, Steven.

"The demon that turned into worms:" the translation of public health in the British Caribbean, 1914-1920. História, Ciências, Saúde Manguinhos, v.13, v.3, p.571-589. 2006.

PICARD, Jean-Francois.

La Fondation Rockefeller et la recherche médicale. Paris: Presses Universitaires de France. 1999.

PROGRAM..

Program for 1932. Report. RF RG 1.1. 437 K, box 3 , folder 33 (The Rockefeller Archive Centre). 1932.

PUTNAM, Persis.

Letter to Muench. RF RG 1.1. 437, box 7, folder 88 (The Rockefeller Archive Centre). 24 Sept. 1934.

PUTNAM, Persis; SAWARD, Joyce; OPIE, Eugene L.

The spread of tuberculosis in negro families of Jamaica. The American Journal of Hygiene Monographic Series, n.16, p.1-53. 1941.

REPORT...

Report on the study of protective inoculation against tuberculosis in progress in Jamaica, RF RG 1.1, box 4, folder 54 (The Rockefeller Archive Centre). 1938.

REPORT...

Report on Tuberculosis work in Jamaica. Report visit May 5 to 13 1932. RF RG 5.2, box 43, folder 263 (The Rockefeller Archive Centre). 1932.

REPORT...

Report of the Kingston Tuberculosis Dispensary. Report quarter ending March 31/32, RF RG 5.3, box 183, folder 2275 (The Rockefeller Archive Centre). 1931-1932.

REPORT...

Report on tuberculosis field survey. Report RF RG 5.3, box 183, folder 2271 (The Rockefeller Archive Centre). 1931.

REVERBY, Susan M.

Ethical failures and history lessons: the U.S.

Public Health Service research studies in

Tuskegee and Guatemala. Public Health Reviews, v.34, n.1, p.1-18. 2012.

REVERBY, Susan M.

Inclusion and exclusion: the politics of history, difference, and medical research. Journal of the History of Medicine and Allied Sciences, v.63, n.1, p.103-113. 2007.

SMITH, Hugh $\mathrm{H}$.

Letter to Putnam. RF RG 1.1. 437, box 6, folder 79 (The Rockefeller Archive Centre). 29 Oct. 1932. 
WASHBURN, Benjamin.

Letter to Sawyer. RF RG 1.1. 437, box 8, folder

101 (The Rockefeller Archive Centre). 4 Jul. 1938.

WASHBURN, Benjamin.

Diary. RF RG 12, box 493, folder Washburn (The

Rockefeller Archive Centre). Oct. 1936.

WASHBURN, Benjamin.

Letter to Russell. RF RG 1.1. 437, box 6, folder 72 (The Rockefeller Archive Centre). 12 Aug. 1931.

WASHBURN, Benjamin.

Letter to Howard. RF RG 1.1. 437, box 6, folder 70 (The Rockefeller Archive Centre). 24 Mar. 1931.

WASHBURN, Benjamin.

Letter to Howard. RF RG 1.1. 437, box 6, folder 69 (The Rockefeller Archive Centre). 5 Feb. 1931.

WASHBURN, Benjamin.

Letter to Howard. RF, RG 5, 1.2 box 302, folder 3831 (The Rockefeller Archive Centre). 5 Dec. 1927.

WASHBURN, Benjamin.

Letter to Wilson. RF, RG 5, 1.2 box 302, folder 3831 (The Rockefeller Archive Centre). 6 Jul. 1927.

WASHINGTON, Harriet A.

Medical apartheid dark history of medical experimentation on black Americans from colonial times to the present. New York: Anchor Books. 2006.

WEIR, John.

Diary. RF RG 12, box 506, folder Weil (The

Rockefeller Archive Centre). 1939.

WELLS, Clifford W.

Letter to Washburn. RF RG 1.1. 437, box 6, folder 69 (The Rockefeller Archive Centre). 2 Feb. 1932.
WELLS, Clifford W.; FLAHIFF, E.W.

Results obtained with heat killed tubercle bacilli administered to persons in a general population. The American Journal of Hygiene, v.40, n.2, p.109115. 1944.

WELLS, Clifford W.; FLAHIFF, Edward Waller; SMITH, Hugh H.

Results obtained in men with the use of a vaccine with heat-killed tubercle bacilli. American Journal of Hygiene, v.40, n.2, p.116-126. 1944.

WELLS, Clifford W.; FLAHIFF, Edward Waller; SMITH, Hugh H.

Protective inoculation against human tuberculosis with heat-killed tubercle bacilli. American Journal of Hygiene, n.29, p.155-164. 1939.

WHITMARSH, Ian.

American genomics in Barbados: race, illness, and pleasure in the science of personalized medicine. Body\&Society, v.17, n.2-3, p.159-181. 2011.

WILSON, William.

Letter to Washburn. RF, RG 5, 1.2 box 302, folder 3831 (The Rockefeller Archive Centre). 11 Nov. 1927.

WILSON, William.

Letter to Washburn. RF, RG 5, 1.2 box 302, folder 3831 (The Rockefeller Archive Centre). 14 Jul. 1927.

WORBOYS, Michael.

Tuberculosis and race in Britain and its Empire, 1900-50. In: Ernst, Waltraud; Harris, Bernard (Ed.). Race science and medicine, 1700-1960. London; New York: Routledge. p.144-66. 1999.

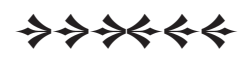

